\title{
Public Attitudes toward Forest Policy Issues: An Analysis of Attitude Structure using Survey Data
}

\author{
Tadashi Kondo*1 and Ichiro Fujikake*2
}

\begin{abstract}
Recent research has been aimed at understanding public attitudes towards foresty policy. Although a number of surveys have gathered many responses to simple questionnaires about relevant issues, no studies have tried to explore the complex nature of public beliefs and thoughts on forest policy related issues. The purpose of the present paper is to further our understanding of public attitudes toward forest policy by examining the structure of the public's attitudes. Our focus is the public support of forest managment.

The analysis using contingency tables and logit equations identified some typical internal relationships between attitude components in the respondent's overall attitude toward the issues. Our major findings were that firstly, agreement with public support for forest management by both monetary contribution and voluntary work was related to a belief in the need for silvicultural treatments to keep forests healthy, a belief in the consumer's responsibility, and appreciation of the values of the forest environment. Secondly, the people who supported voluntary work were a subset of the people who agreed to monetary support. Agreement with public support by voluntary work also seems to be characterised by particular kinds of personal tastes, particulary strong interests in nature.
\end{abstract}

Keyword: attitudes, forest policy, public participation, cost-sharing, volunteer

\section{INTRODUCTION}

It has been shown in a number of survey results that city residents are becoming more aware of the importance of forests as an indispensable component of the living environment. Furthermore, some survey results have shown that many citizens are willing to help forest management by sharing some of management costs needed to keep forests healthy (e.g. the results of the latest nationwide survey as summarized by the Prime Minister's Office (1996)). Besides the willingness to raise funds, a small but significant number of people now take part in the tours to mountain villages to support forest management by working voluntarily in the forest. Some people even move to

*1 National Forest General Affairs Dept., For estry Agency, 1-2-1 Kasumigaseki, Chiyodaku, Tokyo 100 Japan

*2 Graduate School of Agriculture, Kyoto University, Kitashirakawa-Oiwake-Cho, Sakyo$\mathrm{ku}$, Kyoto 606-01 Japan mountain villages from urban areas and get jobs at forestry related employers such as forest owners' associations.

Increased environmental awareness after the period of rapid economic growth has made people more concerned about how to manage and use forests and various recreational activities in forests are now more popular than ever. These trends are apparently enhanced by the incessant flow of information about relevant topics, through all forms of media. It is noteworthy that the vast information flow through the mass-media seems to have not only activated people's concerns about forests, but has also played a significant role in the construction of people's knowledge, beliefs, and opinions on forests and forest policy related issues (AKASAKA 1995). On the other hand, timber production is now extremely unprofitable. Forestry employers can only offer very low wages to workers, in spite of the riskiness and difficulty of works in forests, and thus there are very few entrants to the forestry job market every year. As a result, public support in various forms such as cost-share programs, profit sharing, and volunteer programs becomeof critical importance to forest manage- 
ment in many situations, both on public and private lands. Taking into consideration both public willingness to support forest management and the management's need of support, it is now apparent that the public is beginning to take an important role in forest management and forest use in Japan.

As urban people come to have their own beliefs and opinions on forests and forest policy related issues and even become involved in forest management in some cases, it is important to understand public attitudes toward forest policy. Accordingly, a number of questionnaires have been done by both researchers and governments (e.g. see a review by AKASAKA (1987)). Although these surveys have supplied many results to simple questions, no studies have been made to try to explore the complex nature of public beliefs and thoughts on the forest policy related issues.

The international attitude comparison studies organized by Shidei, Ishida, and Kitamura may be the first large -scale and comprehensive investigation of public attitudes toward forest environment (Shidei 1981, Kitamura 1986). Their survey focused on the differences in feelings, preferences, and opinions regarding forests and forest management between four developed countries: Japan, Germany, France, and Sweden. The major findings were that attitudes toward forest environment are a result of the natural settings and national characteristics such as religion and popular recreational activities. They also reported some differences in attitude which were seemingly related to the size of the city of residence, specifically differences observed between people in Tokyo and in other parts of Japan. Hence, while they found that the social and natural environments were important determinants of the attitudes toward the forest environment, they did not explicitly deal with internal organization of attitude, nor focus on policy issues.

AKASAKA (1987, 1995) suggested that attitudes toward forests are complex. Based on questionnaire results provided by several local and Japanese governments, he inferred that some responses in questionnaires seem to be based on the respondents' actual experience, but others based on knowledge acquired through education and information transmitted by mass-media. However he didn't study the internal organization of attitude.

Owing to the information provided through the media and education, and from people's actual experiences in forest, it is reasonable to assume that people have more or less a set of knowledge, beliefs, and opinions on forests and forest policy related issues. HAYASHI (1979, 1996) investigated the structure of attitude toward nature using a quantification method. He found that whether one agrees or not to treating forests is not related to one's religious attitudes, and that the attitudes of people living in Tokyo that maintaining forests beautiful reqired the recession of human treatments is related to a feeling of awe toward nature. These were the first attempts to deal explicitly with the internal structure of attitude toward nature. Our concern is more specific to forest policy related issues. By examining the internal state of public attitudes toward the forest policy related issues, the purpose of the present paper is to further our understanding of public attitudes toward the issues, with a particular focus on the issue of public support for forest management. We first discuss the theoretical framework used to investigate attitudes which are complex in nature, referring to social psychology literature on attitude, in particular the multicomponent view of attitude and the theories on consistency in attitude structure. Then we examine the relationships between attitude components toward forests and forest policy issues, analyzing the results of a questionnaire we conducted in Otsu, Shiga.

\section{THEORETICAL FRAMEWORK}

The concept of attitude is dominant in social psychology, because attitude is supposed to influence, or at least have something to do with, human behavior, the major concern of psychology. As Schlegel and DiTEcco (1982) observed, the literature concerning the attitude-behavior relationship suggests that attitude needs to be viewed as being 'comprised of a multicomponent structure with these various components having a differential validity for external criteria, including behavior'. Although the definition of attitude has provoked a great deal of controversy and is still controversial, the most common view defines attitude in terms of three distinct types of evaluative response to an attitude object: affective, cognitive, and behavioral responses. Affective responses are expressions of feelings such as liking or disliking, or any kinds of physiological responses to the attitude object; cognitive responses consist of beliefs and thoughts regarding the attitude object; and behavioral responses can be measured by overt actions, or by verbal expressions of behavioral intentions towards the attitude object (Hewstone and STEMPHESon 1996). The attitude object can be anything from a physical entity to an abstract idea.

Although there are no strong objections to this type of three dimensional or tripartite model of attitude, and the definition is referred to widely, from introductory texts to research articles, the validity of tripartite model is not conclusive. Empirical results provide equivocal evidences, as shown by the controversy in BAGOzZI and BURNKRANT 1979, Dillon and Kumar 1985, and BAGOzzi and BurN. KRANT 1985. In relation to the validity of the tripartite model, it is reasonable to suppose that the convergency and divergency between the three dimensions of attitude depends on the attitude domain studied. Further, the relevance of affective, cognitive, or behavioral dimension 
varies with the attitude domain of interest (OLSON and ZANA 1993). For example, whilst a variety of affective evaluations are obtained when the attitude domain is, say, a friend of the participants, affective evaluations are less meaningful when the attitude domain is an abstract idea such as some policy issues. In addition, as BRECKLER (1984) discussed, for some attitude domains it seems impossible to measure affective responses in a form other than a written or verbal response. Because the written or verbal response has passed through subject's cognitive system, the affective and cognitive responses become empirically indistinguishable in a strict sense.

Thus, depending on the attitude domain examined, the tripartite model of attitude isn't equally suitable to and doesn't always facilitate the analysis of empirical results. Nevertheless, the following four points should be noted in relation to the idea of tripartite or multidimensional model of attitude. First, attitude is defined in terms of evaluating responses to some attitude object. Second, the evaluative responses can take various forms, affective, cognitive, or behavioral form. Thus any information derived from observing affective, cognitive, and behavioral responses may be useful for infering the subject's attitude. As mentioned above, the relevant classes of response vary with the attitude domain studied. Third, ScHlEgel and DITECCO (1982) stated that 'a large number of cognitions and beliefs may exist in relation to any given attribute object or action.' Structure of attitudes system is the main focus of attitude research in the 1980s and 1990s (MCGUiRE 1985). Finally, it has not been explicitly mentioned above, but it is commonly assumed that there is, to some extent, convergency or consistency between attitude components. This point will be discussed further in relation to consistency theory. But before doing so, it seems to be valuable to discuss the implications of the above points to forest policy issues.

For our case, since it concerns rather abstract ideas about forest policy, it is reasonable to expect that the responses will be mostly the cognitive, and affective responses, like reflexes or any kinds of physiological responses, are less relevant. Moreover, since the issues are general and contain various points of argument, it is plausible to assume that attitudes toward forest policy related issues consist of a fairly complex set of beliefs and opinions which may be interrelated. For instance, the extent that people agree with the idea that 'forests should be preserved without allowing any harvesting', may be correlated with their beliefs on the impacts of harvesting on the forest ecosystem, the functions of the forest ecosystem, or the need for silvicultural treatments to maintain a healthy forest. It is also plausible that attitudes may be related to whether someone likes or dislikes natural forests. Thus, some kinds of affective responses may be relevant to understanding people's attitude structure, or predicting cognitive responses. Likewise, past experience or behavioral intentions concerning forests might provide information useful for examining cognitive responses to forest policy related issues. Therefore it seems worthwhile examining a broad range of responses concerning forests and forest policy issues as a whole. However, it should be noted that the implicit assumption in this type of analysis is that there is a consistency between response elements, and that we can understand the relationships between the elements in reasonable way.

It is common to presume that there is some degree of consistency between affective, cognitive, and behavioral components. This is especially the case when the elements of attitude are allowed to go through and be mediated by one's cognitive system, or in other words, one is allowed to have chance to reflect on the relations among attitude elements (BRECKLER 1984). Further, the more frequently the attitude object is thought about, the more likely a consistency is to be observed (BRECKLER and WIGGINS 1989). When the cognitive system plays a role in develop-

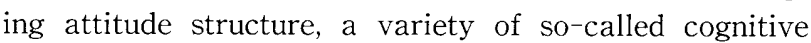
consistency theories provide theoretical underpinnings to the presumption of consistency or congruity between attitude elements; affective-cognitive consistency theory (Rosenberg 1960), balance theory (HEIDER 1946), symbolic psycho-logic theory (ABELSON and ROSENBERG 1958). All consistency theories resemble each other in that they rely on the assumption that people are uncomfortable with inconsistency; when there is inconsistency in one's attitude structure, a person feels uneasy, and will modify some of the attitude components to restore consistency.

To examine consistency in attitude structure, Schlegel (1975) and Schlegel and DiTecco (1982) analyzed attitudes toward marijuana use, and showed that increases in complexity of attitude structure 'did not necessarily result in greater inconsistency and less structure'. With increased marijuana involvement, cognitive activity about marijuana use expanded and accordingly the complexity of attitude structure typically became greater. However, this was not necessarily followed by inconsistencies in attitude. That is, the extent to which elements in the attitude space were related to each other was fairly stable across the different levels of marijuana involvement. In the case of forest policy issues, people usually have a variety of experiences and knowledge of forests, forestry, forest management, and forest policy; whether it is by way of mass-media, education, or direct experience. Thus, attitude structure, especially the cognitive component of it, i.e., knowledge, beliefs, and thoughts, can be differentiated and complex, but it doesn't necessarily mean public attitude toward forest policy are inconsistent.

Therefore, even if people's beliefs are inconsistent with scientific knowledge, or different people have different attitudes, we don't see any transcendental reason to 
expect inconsistent between attitudes about forest policy. Assuming that total dissonance or inconsistency in attitude structure which cannot be understood in any reasonable way is unusual, it seems interesting to study the internal state of attitude structures regarding forests or forest management issues. Although there are a good number of studies done to delineate public opinions on forest or forest management (both by researchers and governments), few attempts have been made to describe attitude structures regarding forests or forest management issues.

\section{DATA AND METHODS}

A questionnaire was conducted in Otsu, Shiga in November, 1995. Otsu is the capital city of Shiga prefecture and is next to the city of Kyoto. It is fairly urbanized and has a populatioin of 270,000 . Otsu faces to the Lake of Biwa, the largest lake in Japan, which has been repeatedly the focus of attention in terms of its water pollution. It is sometimes said that the people in Otsu have relatively high environmental awareness compared to most Japanese. This characteristic of the city may have affected the responses in our survey, but it does not prevent the analysis of internal state of attitude structures regarding forests and forest policy.

We wanted to study the attitudes of people living in urban areas, and as the city includes forested areas like Mt. Hiei on its outskirts, we surveyed only people from the town plannning area of Otsu. We selected 15 neighborhoods from this area using a table of random numbers. In each neighborhood, surveyors dropped a questionnaire into the mail box of each house starting from a randomly selected point. The sample size was 820 , of which 442 responses were available for analysis. The characteristics of the sample population, in terms of sex and age, are summarized in Table 1.

The questionnaire consisted of 48 questions, of which 10 directly concerned forest policy issues. The following BLF1 to BLF10 are the 10 statements, and for each we asked if one agrees, disagrees, or is uncertain. The statements concerning urban people's contributions to forest

Table 1 Characteristics of the sample population

\begin{tabular}{rrr}
\hline Sex & $\begin{array}{c}\text { male } \\
\text { female }\end{array}$ & $\begin{array}{r}273(62) \\
165(37)\end{array}$ \\
\hline Age & $\leq 20$ & $8(2)$ \\
& $20<\leq 40$ & $85(20)$ \\
& $40<\leq 60$ & $192(45)$ \\
& $60<$ & $145(34)$ \\
\hline
\end{tabular}

Note: Percentages in parenthesis management are BLF9 asking about monetary contribution and BLF10 asking about voluntary work.

BLF1. Urban people should know more about forests, such as the make-up or system of forests including animals and plants in forest.

BLF2. Urban people should know more about the human use of forests, such as timber production.

BLF3. Japan should import all timber it consumes and use domestic forests exclusively for land conservation and recreation.

BLF4. Depopulation of rural areas induces degradation of forests.

BLF5. Harvesting helps maintain healthy forests.

BLF6. Forests should be preserved by keeping humans out.

BLF7. Forests should be managed using treatments.

BLF8. The present generation should reduce timber consumption for the sake of future generations.

BLF9. Urban people should contribute money to implement treatments in forests.

BLF10. Urban people should help implementing treatments in forests by volunteering to do some of the work.

In the analysis presented below, our main focus is on the attitudes about public support of forest management; especially BLF9 concerning monetary contribution and BLF10 concerning the public support in the form of volunteer work. We first analyze interrelations between the 10 statements using two-way contingency. tables. The twoway contingency table is a simplistic way of analyzing dependency between two factors because other variables which affect the two analyzed factors aren't controlled. However, one to one dependent relations between beliefs are easily checked in contingency tables. We then developed two logit equations (AGRESTI 1990); one using BLF9 as dependent variable and the other BLF10. In these two equations, variables representing the respondent's past experiences and behavioral intentions as well as belief variables are included as independent variables.

\section{RESULTS AND DISCUSSION}

Dependencies

Table 2 shows the responses to the 10 forest policy questions. Most people agreed with some of the statements, such as BLF1, BLF2, and BLF7, but statements like BLF5 and BLF6 and the statements about public support, BLF9 and BLF10, were contentious. To examine the relation- 
ships between beliefs, we made two-way contingency tables for each parir of statements, and tested the independency of the contingency tables. Table 3 summarizes the $\mathrm{P}$ -values for the chi-square tests of independency. The smaller the $\mathrm{P}^{-}$value is, the greater the possibility that there is dependency between the two beliefs tested. Focusing on the public support issue, four points emerge about the relationships between beliefs.

Whilst BLF9 and BLF10 asked about the pros and cons of urban people's contribution to silvicultural treatments, BLF7 asked about the necessity of such treatments for managing forests. Therefore it isn't surprising that the response to $\mathrm{BLF} 7$ was related to the responses to both BLF9 and BLF10 (Table 3). Tables 4, 5, and 6 show the contingency tablefor each combination of BLF7, BLF9, and BLF10. Examination of these tables reveals that most people who favored urban people's contribution to forests, either by funding or by voluntary work, believe in the need of silvicultural treatments to manage forests. Also, most people who favored the contribution by voluntary work also favored a monetary contribution. These relationships can be summarized as follows.

Table 2 Patterns of agreement and disagreement to belief questions

\begin{tabular}{rrrr}
\hline & Agree & Disagree & Uncertain \\
\hline BLF 1 & $415(94)$ & $8(2)$ & $17(4)$ \\
BLF 2 & $410(93)$ & $12(3)$ & $18(4)$ \\
BLF 3 & $73(17)$ & $298(68)$ & $65(15)$ \\
BLF 4 & $375(85)$ & $34(8)$ & $30(7)$ \\
BLF 5 & $139(32)$ & $213(49)$ & $80(19)$ \\
BLF 6 & $210(48)$ & $150(34)$ & $78(18)$ \\
BLF 7 & $390(89)$ & $22(5)$ & $27(6)$ \\
BLF 8 & $340(78)$ & $34(8)$ & $61(14)$ \\
BLF 9 & $279(64)$ & $52(12)$ & $108(25)$ \\
BLF10 & $147(34)$ & $149(34)$ & $140(32)$ \\
\hline
\end{tabular}

Note: Percentages in parenthesis \{people who agree to BLF7\} $\supseteq\{$ people who agree to BLF9\} $\supseteq\{$ people who agree to BLF10 .

Thus, the results support the supposition that support for urban people contributing to silvicultural treatments is based on the belief that such treatment is necessary. The result that agreeing to BLF10 implies agreeing to BLF9 is not necessarily intuitive, but since voluntary work is a more direct commitment to forest management than a monetary contribution, it suggests that people who agree to both BLF9 and BLF10 are more involved in managing forests than people who agree to BLF9 only.

$\mathrm{BLF} 8$ asked whether one agreed with the reduction in

Table 4 Contingency table between BLF7 and BLF9

\begin{tabular}{cccc}
\hline & & \multicolumn{2}{c}{ BLF7 } \\
& & Agree & Disagree \\
\hline \multirow{2}{*}{ BLF9 } & Agree & 266 & 7 \\
& Disagree & 40 & 10 \\
\hline
\end{tabular}

Note: $\mathrm{P}-$ value $=0.000$

Table 5 Contingency table between BLF7 and BLF10

\begin{tabular}{cccc}
\hline & & \multicolumn{2}{c}{ BLF7 } \\
& & Agree & Disagree \\
\hline \multirow{2}{*}{ BLF10 } & Agree & 141 & 4 \\
& Disagree & 128 & 12 \\
\hline
\end{tabular}

Note: $\mathrm{P}-$ value $=0.033$

Table 6 Contingency table between BLF9 and BLF10

\begin{tabular}{cccc} 
& & \multicolumn{2}{c}{ BLF9 } \\
& & Agree & Disagree \\
\hline \multirow{2}{*}{ BLF10 } & Agree & 127 & 7 \\
& Disagree & 79 & 43 \\
\hline
\end{tabular}

Note: $\mathrm{P}-$ value $=0.000$

Table 3 P-values for chi-square tests of independency between pairs of beliefs

\begin{tabular}{lccccccccc}
\hline & BLF2 & BLF3 & BLF4 & BLF5 & BLF6 & BLF7 & BLF8 & BLF9 & BLF10 \\
\hline BLF1 & $*$ & 0.704 & 0.593 & 0.597 & 0.073 & 0.230 & 0.111 & 0.018 & $*$ \\
BLF2 & & 0.745 & 0.903 & 0.048 & 0.362 & 0.504 & 0.033 & 0.135 & $*$ \\
BLF3 & & 0.326 & 0.320 & 0.117 & 0.074 & 0.624 & 0.699 & 0.514 \\
BLF4 & & & & 0.527 & 0.444 & 0.000 & 0.000 & 0.001 & 0.537 \\
BLF5 & & & & 0.243 & $*$ & 0.125 & 0.857 & 0.333 \\
BLF6 & & & & & 0.015 & 0.052 & 0.153 & 0.000 \\
BLF7 & & & & & & 0.453 & 0.000 & 0.033 \\
BLF8 & & & & & & & 0.010 & 0.003 \\
BLF9 & & & & & & & & 0.000 \\
\hline Note: ${ }^{*}$ incapable of testing because of 0 entries in contingency table & & & &
\end{tabular}


current timber consumption for the sake of future generations. This statement also had some relationship to both BLF9 and BLF10 (Tables 7 and 8). One possible explanation is that people who agree with reducing timber consumption are more environmentally concerned and thus are more likely to be willing to contribute to managing the nation's forests. Alternatively people who agree with reducing timber consumption may have some sense of guil as consumers, and thus feel a responsibility to contribute to forest management.

BLF4, which asked if one believed depopulation in rural area causes forest degradation, was also found to be related to BLF9 (Table9). This dependency suggests that people who agree with this causality are more likely to agree to monetary contribution than those who deny the causality. There may be a belief that healthy forests are maintained by rural people and that urban people should help them by giving monetary assistance.

Agreement with BLF10 (voluntary work) wes also associated with agreement in BLF 6 , which asked if one thinks forests should be preserved by keeping humans out (Table10). There is no obvious explanation for why the two beliefs are connected, but since BLF6 suggests a strong environmental position, the significant overlap between those who agree with BLF6 and those who agree with BLF10 might suggest that people who agree with BLF10 have the strong environmental concerns. However, it should be noted that although a belief in the strict preservation of forest is related to agreeing with voluntary work, a belief in the compatibility between timber harvesting and forest health (BLF5) is not related to a belief in voluntary work. The statement of BLF5 suggests that wise use is a form of conservation, whereas BLF6 suggests a belief in preservation. Thus it appears that those who support voluntary work are more likely to be those who support preservation, rather than conservation through wise use.

Beliefs, Experiences, and Intentions

The multicomponent view of attitude, coupled with the consistency theory, suggests that beliefs about forest policy issues are related to the affective and behavioral components of a person's attitude toward forests. Although we could not obtain appropriate variables to measure the affective responses, we did gather some data on the respondents' past experiences and behavioral intentions. Combining these data with the above results, we estimated logit equations for the likelihood of favoring public support for forest management, to see what attitude elements are related to the formation of opinions about forest management. One equation estimates the likelihood of agreeing to monetary contributions, and the other estimates for the likelihood of agreeing to voluntary work. Since more than one attitude component seems to simultaneously affect the
Table 7 Contingency table between BLF8 and BLF9

\begin{tabular}{cccc}
\hline & & \multicolumn{2}{c}{ BLF8 } \\
& & Agree & Disagree \\
\hline \multirow{2}{*}{ BLF9 } & Agree & 230 & 18 \\
& Disagree & 38 & 9 \\
\hline
\end{tabular}

Note: $\mathrm{P}-$ value $=0.010$

Table 8 Contingency table between BLF8 and BLF10

\begin{tabular}{cccc}
\hline & & \multicolumn{2}{c}{ BLF8 } \\
& & Agree & Disagree \\
\hline \multirow{2}{*}{ BLF10 } & Agree & 134 & 6 \\
& Disagree & 107 & 19 \\
\hline
\end{tabular}

Note: $\mathrm{P}-$ value $=0.003$

Table 9 Contingency table between BLF4 and BLF9

\begin{tabular}{cccc}
\hline & & \multicolumn{2}{c}{ BLF4 } \\
& & Agree & Disagree \\
\hline \multirow{2}{*}{ BLF9 } & Agree & 249 & 40 \\
& Disagree & 15 & 10 \\
\hline
\end{tabular}

Note: $\mathrm{P}-$ value $=0.001$

Table 10 Contingency table between BLF6 and BLF10

\begin{tabular}{cccc}
\hline & & \multicolumn{2}{c}{ BLF6 } \\
& & Agree & Disagree \\
\hline \multirow{2}{*}{ BLF10 } & Agree & 95 & 55 \\
& Disagree & 43 & 67 \\
\hline
\end{tabular}

Note: $\mathrm{P}-$ value $=0.000$

formation of opinions, a logit model is a more appropriate way of investigating complex relationships between attitude elements than a simple two-way contingency table.

Table 11 shows the maximum likelihood estimation results for the two logit equations. Before discussing the results, the dependent and independent variables should be explained. One dependent variable represents the likelihood of agreeing to monetary contribution. It is a dummy variable coded 1 if the respondent agreed to BLF9, or 0 if the respondent disagreed to BLF9. The other dependent variable is also a dummy variable which represents the respondent's attitude towards voluntary work (BLF10).

Eleven variables were selected as independent variables. These are summarized in Table 12. The variables BLF6 to BLF8 are defined in the same way as the dependent variables, and were included because the above results verified that the response patterns to these issues were related to the responses to BLF9 and/or BLF10. The variables with names begining with EXP indicate the expe- 
Table 11 Coefficients and $t$-values for variables in logit equations modelling agreement with public support for forest management by monetary contribution (BLF9) and voluntary work (BLF10)

\begin{tabular}{|c|c|c|}
\hline \multirow[b]{2}{*}{ Variable } & \multicolumn{2}{|c|}{ Dependent variable } \\
\hline & BLF9 & BLF10 \\
\hline Constant & -2.515 & -4.844 \\
\hline BLF6 & $\begin{array}{c}0.641 \\
(1.601)\end{array}$ & $\begin{array}{l}1.285^{* * *} \\
(2.908)\end{array}$ \\
\hline BLF7 & $\begin{array}{l}2.410^{* * *} \\
(3.647)\end{array}$ & $\begin{array}{l}1.741^{* *} \\
(2.450)\end{array}$ \\
\hline BLF8 & $\begin{array}{l}1.188^{* *} \\
(2.264)\end{array}$ & $\begin{array}{l}1.735^{* * *} \\
(2.930)\end{array}$ \\
\hline EXPCLT & $\begin{array}{c}0.793 \\
(1.093)\end{array}$ & $\begin{array}{c}0.860 \\
(1.582)\end{array}$ \\
\hline EXPFRY & $\begin{array}{l}-0.997^{* *} \\
(-2.526)\end{array}$ & $\begin{array}{c}-0.461 \\
(-1.427)\end{array}$ \\
\hline EXPLRN & $\begin{array}{c}0.924^{*} \\
(1.852)\end{array}$ & $\begin{array}{l}0.877^{* *} \\
(2.376)\end{array}$ \\
\hline INTCLT & $\begin{array}{c}1.041 \\
(1.258)\end{array}$ & $\begin{array}{c}0.658 \\
(1.207)\end{array}$ \\
\hline INTFRY & $\begin{array}{c}0.226 \\
(0.197)\end{array}$ & $\begin{array}{l}12.794 \\
(0.077)\end{array}$ \\
\hline INTLRN & $\begin{array}{c}-0.014 \\
(-0.026)\end{array}$ & $\begin{array}{c}0.720^{*} \\
(1.704)\end{array}$ \\
\hline INTMOV & $\begin{array}{c}0.875 \\
(1.293)\end{array}$ & $\begin{array}{l}1.016^{* *} \\
(1.967)\end{array}$ \\
\hline INTTIM & $\begin{array}{c}-1.547 \\
(-1.199)\end{array}$ & $\begin{array}{c}-2.382^{*} \\
(-2.382)\end{array}$ \\
\hline $\ln L($ null $)$ & -111.12 & -162.50 \\
\hline $\ln L($ model $)$ & -95.11 & -132.00 \\
\hline 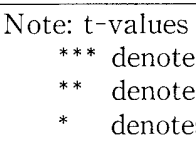 & $\begin{array}{l}\text { arenthesis } \\
\text { nificance at } t \\
\text { nificance at } t \\
\text { nificance at } t\end{array}$ & $\begin{array}{l}\text { level } \\
\text { level } \\
\text { level }\end{array}$ \\
\hline
\end{tabular}

riences of the respondent. In the questionnaire there were 31 outdoor activities listed and we asked respondents to check all activities that they had done in private but not as extracurricular activities in schools. The 31 activities are divided into 5 groups according to the type of activity. The variable EXPCLT represented collecting activities and was coded 1 if the respondent had experienced in collecting mushrooms, wild plants, nuts, and berryies, insects, firewood, or fallen leaves; or 0 if the respondent had not experienced any of these activities. EXPFRY represented forestry activities, and was coded 1 if the respondent had either planted, weeded, or harvested trees; or 0 if the respondent had not experienced any of these activities. EXPLRN represented educational activities, and was coded 1 if the respondent had participated in forestry educational activities or nature watching; or 0 if the respondent had not experienced either. We also included two
Table 12 Independent variables used in logit equations modelling agreement for public support of forest management

\begin{tabular}{|c|c|}
\hline variable & definition \\
\hline BLF6 & $\begin{array}{l}\text { coded } 1 \text { if the respondent agreed that } \\
\text { "forests should be preserved by keeping } \\
\text { humans out"; } 0 \text { otherwise }\end{array}$ \\
\hline BLF7 & $\begin{array}{l}\text { coded } 1 \text { if the respondent agreed that } \\
\text { "forests should be managed using } \\
\text { silvicultural treatments"; } 0 \text { otherwise }\end{array}$ \\
\hline BLF8 & $\begin{array}{l}\text { coded } 1 \text { if the respondent agreed that } \\
\text { "the present generation should reduce } \\
\text { timber consumption for the sake of } \\
\text { future generations", } 0 \text { otherwise }\end{array}$ \\
\hline EXPCLT & $\begin{array}{l}\text { coded } 1 \text { if the respondent had experi- } \\
\text { enced collecting activities; } 0 \text { otherwise }\end{array}$ \\
\hline EXPFRY & $\begin{array}{l}\text { coded } 1 \text { if the respondent had experi- } \\
\text { enced forestry practices; } 0 \text { otherwise }\end{array}$ \\
\hline EXPLRN & $\begin{array}{l}\text { coded } 1 \text { if the respondent had experi- } \\
\text { enced educational activities; } 0 \text { otherwise }\end{array}$ \\
\hline INTCLT & $\begin{array}{l}\text { coded } 1 \text { if the respondent wanted to do } \\
\text { collecting activities; } 0 \text { otherwise }\end{array}$ \\
\hline INTFRY & $\begin{array}{l}\text { coded } 1 \text { if the respondent wanted to do } \\
\text { forestry practices; } 0 \text { otherwise }\end{array}$ \\
\hline INTLRN & $\begin{array}{l}\text { coded } 1 \text { if the respondent wanted to do } \\
\text { educational activities; } 0 \text { otherwise }\end{array}$ \\
\hline INTMOV & $\begin{array}{l}\text { coded } 1 \text { if the respondent wanted to move } \\
\text { to rural area; } 0 \text { otherwise }\end{array}$ \\
\hline INTTIM & $\begin{array}{l}\text { coded } 1 \text { if the respondent wanted to have } \\
\text { forest for timber management; } 0 \text { other- } \\
\text { wise }\end{array}$ \\
\hline
\end{tabular}

other categories of past experience, but these were more common activities (e.g. hiking, camping) than those represented by the three variables above and were not significant in the logit equations They were therefore omitted from the final equations. For each of the 31 activities, we also asked if the respondent wanted to do it in the future if they had never experienced it. The responses were used in the same way as above to construct the variables INTCLT, INTFRY, and INTLRN for the three categories of collecting activities, forestry activities, and educational activities, respectively. Since respondents were asked to check activities that they haven't experienced but would like to, three INT- variables and three EXP- variables should be complementary and represent the respondent's behavioral attitudes towards forests.

Two additional variables representing behavioral intentions were also constructed. Respondents were asked to check any of four things that they wanted to do. Of the four, two were used to further characterize the respondent' $s$ behavioral attitude. The variable INTMOV was coded 1 if the respondent said they wanted to move to a rural area, and the variable INTTIM was coded 1 if the respondent wanted to participate in timber management. 
The behavioral variables, INT- and EXP- represent the respondent's personal tastes or interests, in contrast to the belief variables which represent one's beliefs and opinions on policy related issues. Specifically, all the behavioral variables are related to respondent's nature-orientedness; but different variables are supposed to represent different kinds of nature- ${ }^{-}$rientedness.

The estimated coefficients for BLF7 and BLF8 and associated t-test statistics (Table 10) show that if the respondent agreed to BLF7 (BLF8), they were more likely to agree to BLF9 and BLF10 than those who disagreed with BLF7 (BLF8). This is consistent with the results of the contingency table analysis. We propose that this result suggests that people who recognized the need for silvicultural treatments to maintain healthy forests, or who felt some sense of guilt and thus responsibility as timber consumers, were more likely to be in favor of public support for forest management.

The coefficients of EXPLRN were also significant for both equations, and INTLRN was also positive and significant in the equation for voluntary work. Variables representing collecting and forestry activities did not have significant and positive coefficients. These results suggest that those people who agree with public support for forests are people who regard forests as areas for learning or nature watching. This is consistent with the common observation that in contemporary Japanese society the value of forest to urban peoplelies in the non-economic, environmental functions of forest, rather than the timber and various non-timber productive functions. This contrasts with the traditional values of productive functions for rural communities, which continues to some extent these days (SUGAWARA 1995). Overall, agreement with public support for forest management seemed to be associated with appreciation of the environmental values of forests.

In the equation for voluntary work, the coefficients for BLF6 and INTMOV are positively significant, and that for INTTIM is negatively significant. The contingency table between BLF9 and BLF10 showed that people who agreed to BLF10 were a subset of people who agreed to BLF9. Thus, the variables that are significant only in the equation for voluntary work may help us identify what factors make people agree to not only monetary contribution but also voluntary work. INTMOV represents people who consider moving to rural areas. These people seem to have strong a interest in nature, or be tired of urban life, and yearn for living in rural area surrounded by abundant nature. It is reasonable to suppose that these people are more likely to feel comfortable in forests and are thus less likely to mind working in forest than ordinary people. This probably explains a significantly positive coefficient for INTMOV in voluntary work equation.

Supporters for voluntary work can also be characterised as people who believe in preservation (BLF6) and have no intention of becoming involved in timber management (INTIM). Thus the supporters of BLF10 are typically people who want to keep nature intact. The significantly negative coefficient for INTTIM indicates that supporters of voluntary work do not base their stance on the economic or utilitarian value of forest; i.e. supporters of voluntary work are not interested in timber management. To sum up, people who favor public support for forest management by voluntary work are less likely to be interested in management for timber production, and are more likely to be interested in preserving nature.

\section{CONCLUSION}

We analyzed urban people's attitudes toward forest policy issues based on the multicomponent view of attitude. Swe analysed the relationships between components of attitudes toward public support for forest management by monetary contribution or voluntary work. We used contingency tables and logit equations to describe these relationships. We can gain a better understanding of public opinions on forest policy issues if we can clarify how attitudes are related to each other, i.e. how opinions, beliefs, tastes, and interests in forests are related. This is more effective than just obtaining mere frequencies of occurrences of opinions.

The main findings of our analysis are firstly, that agreement with public supportfor forest management by monetary contribution and agreement with public support by voluntary work are related to beliefs in the need for management to keep forests healthy, consumer responsibility, and the value of the forest environment. Secondly, although these three elements are related to agreement with monetary support and voluntary work, those people who support voluntary work are a subset of those who agree to monetary support. Support for voluntary work also seems to be characterised by particular personal tastes, specifically strong interests in nature. These findings are consistent with the observation that the recent diversification of individual values has resulted in more voluntary forest crews in work.

\section{LITERATURE CITED}

Abelson, R. P. and Rosenberg, M. J., (1958): Symbolic psycho-logic: A model of attitudinal cognition. Behavioral Sciences 3: 1-13

AkasaKa, M., (1987): Japanese forests in the consciousness of the inhabitants (2) Forests or "Midori". Trans. of the Jpn. For. Soc. 98: 71-72 (in Japanese)

AkASAKA, M., (1995) : Forest landscape and the media. In Toui hayashi, chikai mori: changes in the attitudes toward forest and the civilization. Coauthored by Sugawara, S., Kitamura, M., Ichikawa, T., and 
Akasaka, M. Aichi Shuppan, Tokyo, 166pp* (in Japanese)

Agresti, A., (1990): Categorical Data Analysis. Wiley, New York, 558 pp

Bagozzi, R. P. and Burnkrant,R. E., (1979): Attitude organization and the attitude-behavior relationship. Journal of Personality and Social Psychology 37: 913-929

Bagozzi, R. P. and Burnkrant,R. E., (1985):Attitude organization and the attitude-behavior relationship: A reply to Dillon and Kumar. Journal of Personality and Social Psychology 49: 47-57

BRECKLER, S. J., (1984): Empirical validation of affect, behavior, and cognition as distinct components of attitude. Journal of Personality and Social Psychology 47: 1191-1205

Breckler, S. J. and Wiggins, E. C., (1989): Affect versus evaluation in the structure of attitudes. Journal of Experimental Social Psychology 25: 253-271

Dillon, W. R. and Kumar,A., (1985):Attitude organization and the attitude-behavior relationship: A critique of Bagozzi and Burnkrant's reanalysis of Fishbein and Ajzen. Journal of Personality and Social Psychology 49: 33-46

Hayashi, C., (1979): Statistical methods for the analysis of attitudes toward forest. Trans. Meet. Tohoku Jpn. For. Soc. 30: $1-4^{*}$ (in Japanese)

Hayashi, C., (1996): For the establishment of a new philosophy of forest management and design and analysis of good-quality-data. Jpn. J. For. Plann. 26: 3-16 (in Japanese)

Heider, F., (1946): Attitudes and cognitive organization. Journal of Psychology 21:107-112

Hewstone, M., Stroebe, M. and Stephenson, G. M., (1996): Introduction to social psychology, 2nd edition. Blackwell, Oxford, 698pp

Kitamura, M., (1986): Research on the public attitudes towards the forest environment. Report of the research granted by Grants-in-
Aid for Scientific Research $(59041009$, 60043010). 81pp* (in Japanese)

McGuire, W. J., (1985): Attitudes and attitude change. In Handbook of Social Psychology, 3rd edition, Vol. 2. Edited by Lindzey, G. and Aronson, E. Random House, New York, 1120pp

Olson, J. M. and ZanNA, M. P., (1993): Attitudes and attitude change. Annual Review of Psychology 44:117-154

Rosenberg, M. J., (1960): An analysis of affective-cognitive consistency. In Attitude Organization and Change: An Analysis of Consistency among Attitude Components. Edited by Hoveland, C. I., and Rosenberg, M. J. Yale University Press, New Haven, CT, 239pp

Prime Minister's Office (1996): Public opinion survey on forest and forestry. Rinyajiho 43(3): 1-27* (in Japanese)

Schlegel, R. P., (1975): Multidimensional measure of attitude towards smoking marijuana. Canadian Journal of Behavioral Science 7:387396

Schlegel, R. P. and DiTecco, D., (1982): Attitudinal structure and the attitude-behavior relation. In Consistency in Social Behavior: The Ontario Symposium, Vol. 2. Edited by M. P. Zanna, E. T. Higgrns, and C. P. Herman. Erlbaum, Hillsdale, NJ, 314pp

SHIDEI, T., (1981): International comparisons of attitudes toward nature. Scientific report of Toyota Foundation I-007. 128pp (in Japanese)

Suciawara, S., (1995): Attitudes toward forest in its change. In Toui hayashi, chikai mori: changes in the attitudes toward forest and the civilization. Coauthored by Sugawara, S., Kitamura, M., IchiKawa, T., and Akasaka, M. Aichi Shuppan, Tokyo, 166pp* (in Japanese)

* Titles are tentative translations from the original Japanese titles by the authors of this paper.

(Received 11 July 1996) (Accepted 9 January 1997) 